\title{
Operational aspects of the TanDEM-X Science Phase
}

\author{
Edith Maurer ${ }^{1}$, Ralph Kahle ${ }^{2}$, Falk Mrowka ${ }^{3}$, Gary Morfill ${ }^{4}$, Andreas Ohndorf ${ }^{5}$, Steffen Zimmermann ${ }^{6}$ \\ German Aerospace Center (DLR), Münchner Straße 20, 82234 Wessling, Germany
}

In the years 2010-2014 the satellites TSX and TDX collected all the Synthetic Aperture Radar (SAR) data necessary to fulfill the primary TanDEM-X mission objective: the generation of a global digital elevation model with unprecedented accuracy. In September 2014, when the necessary data set was almost complete, a transition to the so-called science phase took place. Its focus was the implementation of the TanDEM-X secondary mission objectives. TSX and TDX fly in close formation in low Earth orbit in order to form a SAR interferometer in space with adjustable interferometric baselines. Due to the diversity of scientific applications, the science phase was marked by several baseline and hence formation changes and, in addition, by unusual formation geometries. Modifications to the proven operational handling of SAR payloads and the data downlink became necessary as well as the adaptation of existing safety concepts. Furthermore, the transition from one baseline setting to the other had to be managed operationally safe and in such a way that downtimes were minimal.

\section{Nomenclature}

SAR
TanDEM-X Mission
TSX
TDX
TerraSAR- $X$ data takes
TanDEM- $X$ data takes
DLR
DEM
Airbus DS
GSOC
AOL
Delta $v$
v
h
RAAN
DRA
TAFF
GPS

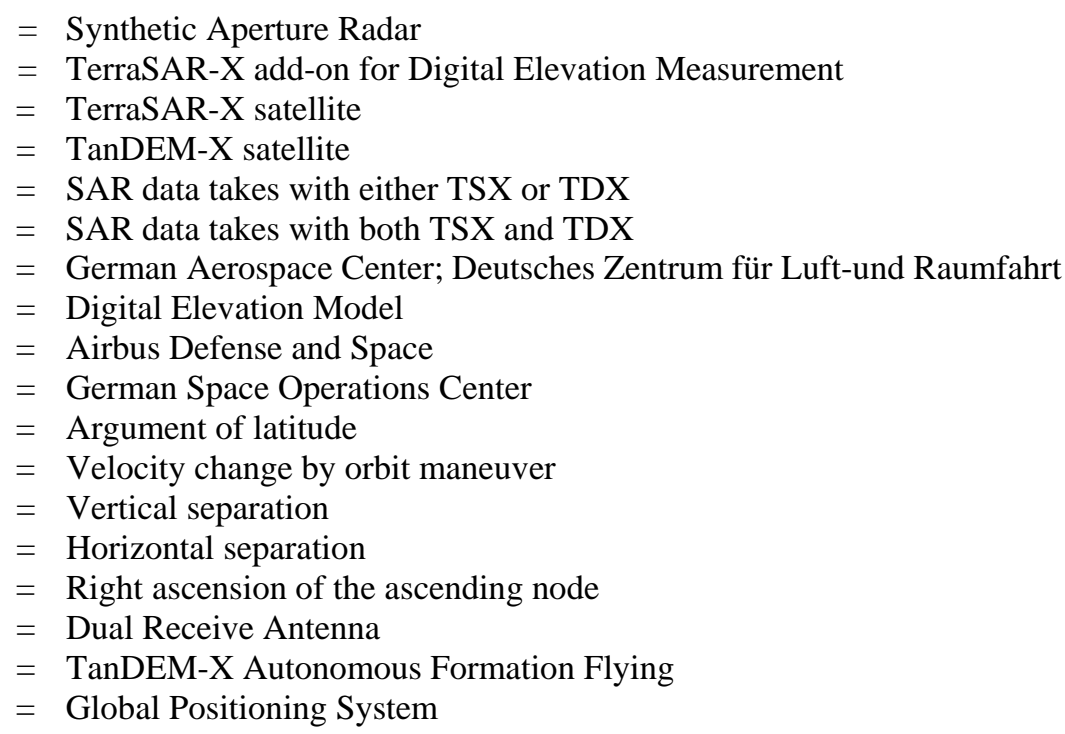

\section{Introduction}

$\mathrm{T}$

HE TanDEM-X (TerraSAR-X add-on for Digital Elevation Measurement) Mission was established in a public private partnership between the partners German Aerospace Center (DLR) and Airbus DS with a project

\footnotetext{
${ }^{1}$ TSX/TDX Project Manager GSOC, German Space Operations Center, Edith.Maurer@dlr.de.

${ }^{2}$ TSX/TDX Flight Dynamics Manager, German Space Operations Center, Ralph.Kahle@dlr.de.

${ }^{3}$ TSX/TDX Mission Planning Manager, German Space Operations Center, Falk.Mrowka@dlr.de.

${ }^{4}$ TSX/TDX Flight Director, German Space Operations Center, Gary.Morfill@dlr.de.

${ }^{5}$ TSX/TDX Flight Director, German Space Operations Center, Andreas.Ohndorf@dlr.de.

${ }^{6}$ TSX/TDX System Engineer, German Space Operations Center, Steffen.Zimmermann@dlr.de.
} 
management by the German Space Agency. The same applies for the prior TerraSAR-X mission which is closely linked to the TanDEM-X project. Both collaborations are continued in a joint TerraSAR-X/TanDEM-X project since 2016.

The spacecraft TSX was launched within the TerraSAR-X mission in June 2007 into a low Earth orbit with $505 \mathrm{~km}$ mean altitude. Synthetic Aperture Radar (SAR) products are delivered to a commercial and scientific user community. Since June 2010, TSX is accompanied by TDX, which was launched in the framework of the TanDEM-X mission. TDX's hardware is to a large extent identical to TSX; both spacecraft were manufactured by Airbus DS. The missions share a joint ground segment ${ }^{1}$, the German Space Operations Center (GSOC) serves as control center for the satellites. The TanDEM-X mission combines the payloads on both satellites to a SAR interferometer in space in order to retrieve data of the Earth's topography ${ }^{2,3}$.The two spacecraft were maneuvered into a so-called close formation flight with typical inter-satellite distances of a few hundreds of meters in October $2010^{4}$. Since then, the Earth's land surface was scanned multiple times to generate a global Digital Elevation Model (DEM). In September 2014, when these data were largely complete, the TanDEM-X project focused on its secondary objectives and started the so called TanDEM-X science phase. The baseline of the space born SARinterferometer TSX-TDX is configurable, more precisely it can be adjusted by means of orbit control. Variations of the baseline in cross-track and in along-track directions are feasible. This enables a large variety of SARapplications and allows SAR methodology research; these opportunities for research should be taken within 17 months especially dedicated to science.

The TanDEM-X science phase is the central topic of this contribution. Chapter III introduces the concept and the requirements. The paper takes the perspective of the mission control center GSOC; thus the focus lies on operational aspects. Chapter IV, the central one within this contribution, details the modifications to operational concepts that became necessary due to the science phase. The basis for this is Chapter II, it introduces to the corresponding standards of the TerraSAR-X/TanDEM-X mission. The systems Flight Dynamics and Mission Planning were worstaffected by the science phase. Flight Dynamics had to handle the frequent formation changes. Mission planning was strongly involved since it schedules payload activities of the TanDEM-X and TerraSAR-X mission on the spacecraft TSX and TDX (see II/A). The TerraSAR-X mission was continued throughout the TanDEM-X science phase. Special attention was put on the constraint that restrictions to the TerraSAR-X users had to be kept to a minimum.

Just as in the overall TanDEM-X/TerraSAR-X mission multiple players are involved into the TanDEM-X science phase. The concept was conceived by the TanDEM-X science segment located at the DLR Microwave and Radar Institute. Arrangement of the science data acquisition plan and the design of appropriate formation geometries were accomplished in this environment as well. Payload data reception and SAR processing was carried out by the DLR Earth Observation Center. Commercial activities of the missions are located at Airbus DS. A close coordination of operational activities with the commercial segment became necessary in case of side effects of the TanDEM-X science phases onto the commercial TerraSAR-X mission.

\section{Two missions, two satellites}

\section{A. TerraSAR- $X$ and TanDEM- $X$ mission modes}

Both missions, TerraSAR-X and TanDEM-X utilize both satellites TSX and TDX. Figure 1 depicts the implemented SAR operations modes. A TerraSAR-X data take is acquired by one satellite only, either TSX or TDX; the collected data are called monostatic (Figure 1a and Figure 1b). Contrary, the TanDEM-X mission data takes use both

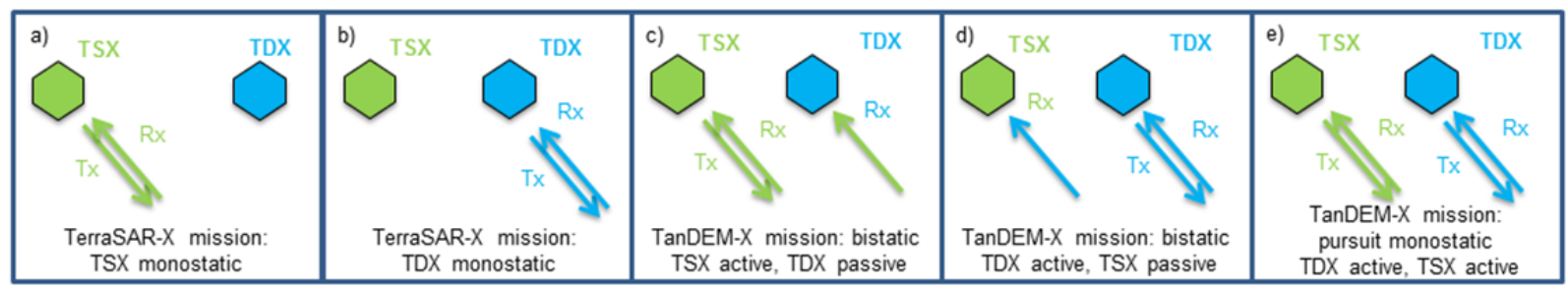

Figure 1. TSX and TDX SAR operations modes within the TerraSAR-X and TanDEM-X mission

TSX and TDX are represented by green respectively blue hexagons modelled after the satellites' cross section in

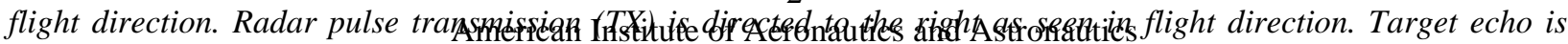
returned and it is recorded by the spacecraft (RX). The parts a) to e) break down how these roles can be assigned. 
spacecraft, either simultaneously (Figure 1c-d) or consecutively (Figure 1e). In the bi-static mode (Figure 1c and Figure 1d) one satellite is selected to be the active partner (transmission and reception of radar pulses), the associated passive role (reception only) is assigned to the partner satellite. Usually, this distribution of tasks between the active and the passive satellite is kept constant throughout a bi-static data take. However, in the so-called alternating bi-static mode the payloads of TSX and TDX are transmitting alternatingly radar pulses, here, the roles are continuously exchanged within a data acquisition process (not shown in Figure 1). In addition, the mode detailed in Figure 1e was applied for some month during the TanDEM-X science phase. TSX and TDX are both active and acquire data independently with a time lag in the so-called pursuit monostatic mode. In order to avoid confusion between missions and spacecraft, the satellites are strictly referred to as TSX and TDX and the missions are referred to as TerraSAR-X and TanDEM-X.

\section{B. Formation flight}

As outlined in Figure 1 the roles of TDX and TSX are symmetrical concerning payload operations. In the matter of formation flight this is different. TSX is controlled in a $505 \mathrm{~km}$ altitude, sun-synchronous dusk-dawn orbit with a repeat cycle of 11 days. The TSX osculating orbit is maintained within a maximum cross-track distance of $250 \mathrm{~m}$ from a target Earth-fixed reference trajectory ${ }^{5}$. TDX, however, is controlled with respect to TSX. Figure 2 sketches the standard formation flight. Considering the plane perpendicular to flight direction, the formation geometry is an ellipse characterized by a maximum vertical or radial separation and a maximum horizontal or normal separation (see Figure 2a). Once per orbital revolution, which takes about 95 minutes, TDX moves in a counter-clockwise elliptical path around TSX. Both vertical and horizontal separations vary with the argument of latitude. The maximum vertical separation is typically most distinct close to the poles and it vanishes at the ascending and descending equator crossings. Contrarily, the maximum horizontal separation is achieved at the equator crossings, whereas it vanishes close to the poles. The formation parameters are always chosen to guarantee a combined crosstrack (i.e. radial and normal) separation larger than a safety threshold of typically $150 \mathrm{~m}$. In addition, TDX moves back and forward with respect to TSX in flight direction (see Figure 2b). Here, the along-track separation of the spacecraft, a function of argument of latitude as well, comes into play. The absolute value of the along-track separation is most distinct at of the equator crossings and vanishes at the poles. Orbit control maneuvers to keep TSX on the TerraSAR-X reference orbit are replicated on TDX. However, formation control maneuvers are solely performed by TDX. Typically, a pair of formation control maneuvers, one in flight direction and one in anti-flight direction, is executed each day to maintain the formation of TSX and TDX ${ }^{6}$.
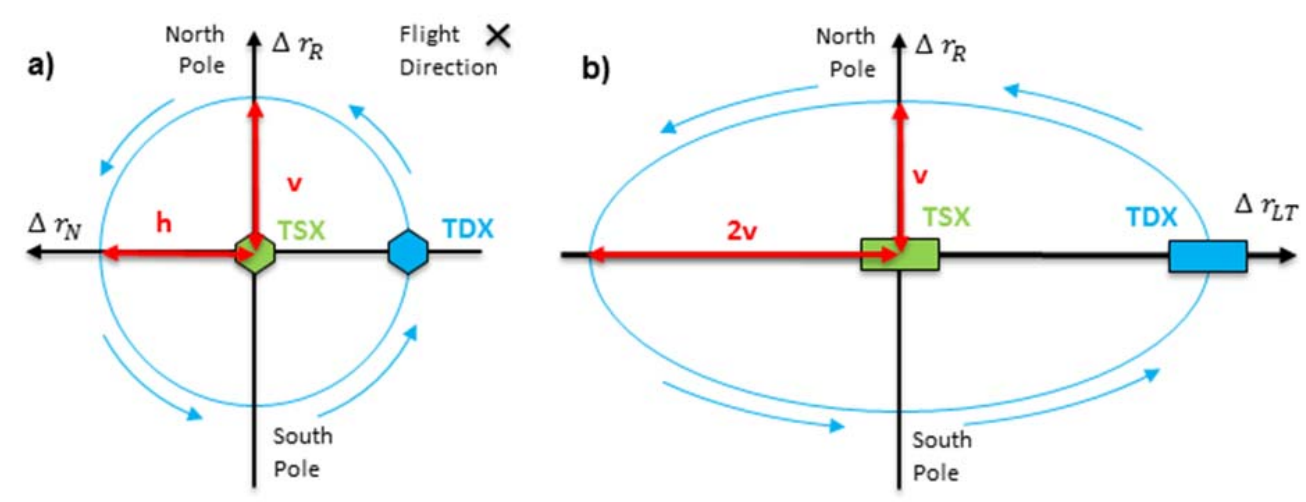

Figure 2 TanDEM-X standard formation flight TSX is located in the center of the coordinate systems; the blue lines describe TDX's motion with respect to TSX. The displacement of TDX in radial, normal and in along-track direction are denoted by $\Delta r_{R}, \Delta r_{N}$ and $\Delta r_{L T}$.

a) Relative motion in the plane perpendicular to the flight direction: $v$ indicates the vertical separation. It is most developed close to the poles. The horizontal separation, $\boldsymbol{h}$, however is maximal at the equator crossing.

b) Relative motion in the orbital plane: The maximal along-track separation is double the size of the vertical separation. The maximal along-track separation is given at the equator crossing. 


\section{Safety aspects}

The formation flight of TSX and TDX pose two major risks ${ }^{7}$ : collision of the spacecraft and exposure of the partner satellite to the transmitted radar beam. Multiple safety features have been implemented within the ground and the space segment to prevent occurrence of such events. The list of safety features detailed here is not complete; it focuses on aspects modified within the TanDEM-X science phase.

\section{1) Exclusion zones}

The partner satellite must not be illuminated by the main lobe radar beam. Therefore, the emission of radar must be prevented in specific parts of the orbit, the so-called exclusion zones. In such an exclusion zone the spacecraft must not perform TerraSAR-X mission data takes and it must not take over the active role within TanDEM-X mission data takes. The size of the exclusion zone within an orbit depends on the formation geometry. The TSX and TDX exclusion zones are complementary. This means at any point in time active transmission is allowed for at least one satellite. Compliance of the payload's timeline with the exclusion zones is checked by three instances, two on ground and one on-board.

2) Limitation of orbit modification by on-board autonomy

In a few cases, safe mode attitude control operations of TSX and TDX can make use of hydrazine thrusters implying the potential for uncontrolled orbit changes. In nominal attitude mode, reaction wheels ensure attitude stability without any orbit modification. In acquisition safe mode attitude control is performed primarily by magnetorquer which again do not cause any momentum change. However, the acquisition safe mode may require assistance for attitude control by on-board autonomous thruster operation. In this case, the orbit of the satellite in safe mode is altered. In order to access implications on exclusion zones, the sync warning mechanism has been established (see section 3). Additionally, the risk of a collision caused by onboard autonomous thruster usage has been ruled out to a very large extent. An upper limit for the allowed velocity change in safe mode is implemented such to guarantee a minimal cross-track threshold between TSX and TDX (e.g. $70 \mathrm{~m}$ ). Only in highly improbable cases, e.g. none of a series of recovery actions was successful; this velocity change limit may be exceeded. The setting of the velocity change threshold depends on the formation geometry.

\section{3) Sync warning mechanism}

The three instances of exclusion zone checks are based on the assumption that the ground calculated relative orbit of TSX and TDX corresponds to the reality in space. As a consequence safety against mutual $\mathrm{RF}$ illumination is not given for TSX or TDX in case the partner satellite experiences a safe mode drop, and therefore a potential orbit alternation caused through on-board autonomy actions. Sync warning data takes are a bi-directional exchange between the radar payloads of both satellites. One bit of information, namely whether a safe mode drop has occurred or not, is carried. In case of a safe mode drop of the partner radar transmission is completely suppressed for the partner's safety. The frequency of sync warning data takes (e.g. every $53 \mathrm{~min}$ ) is in nominal formation adapted to predictions how soon after a safe mode drop thruster activation for on-board attitude control is conceivable.

\section{Payload ground station network}

TerraSAR-X mission and TanDEM-X mission have a disjoined payload ground antenna network for payload data reception. TerraSAR-X mission payload data are downlinked to Neustrelitz (Germany), Spitzbergen (Norway) or stations of Airbus DS customers. Kiruna (Sweden), O’Higgins (Antarctica), Inuvik (Canada) ground stations act as counterpart for the TanDEM-X mission ${ }^{8}$. All ground stations receive payload data of TSX and TDX spacecraft. In close formation, whenever the angular separation of the spacecraft, as seen from the antenna on ground, is small enough payload data of TSX and TDX are received sequentially from both spacecraft within one pass.

\section{The TanDEM-X Science Phase}

The TanDEM-X science phase started in September 2014, when the data for the DEM were collected. The following 17 months were dedicated to secondary objectives of the TanDEM-X project. The configurable SAR-interferometer TSX-TDX opens-up possibilities for multiple science applications ${ }^{9}$. These applications pose partly contradicting requirements on the interferometric baseline between the two satellites' radar instruments. The sciences phase has been conceived in a way that applications with compatible requirements on the formation were clustered in time. Viewed from the perspective of satellite operations the science phase was characterized by frequent formation 


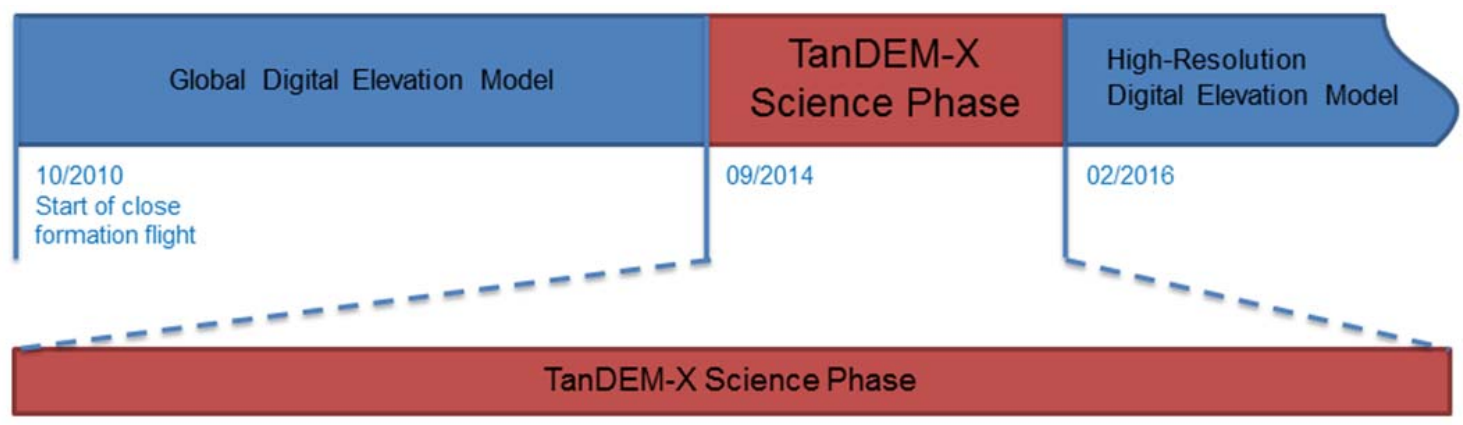

a)

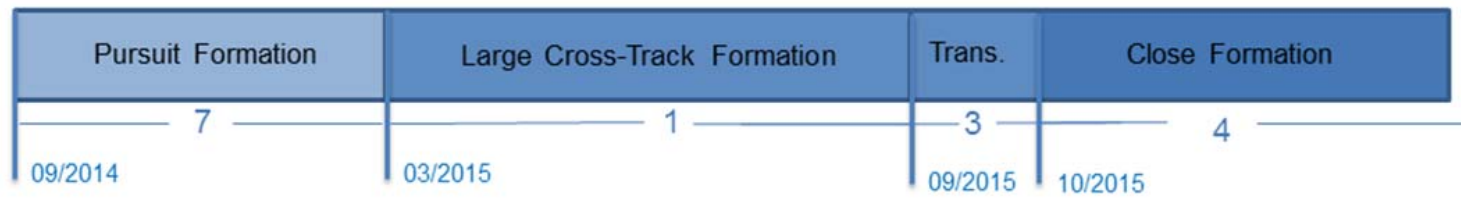

b)

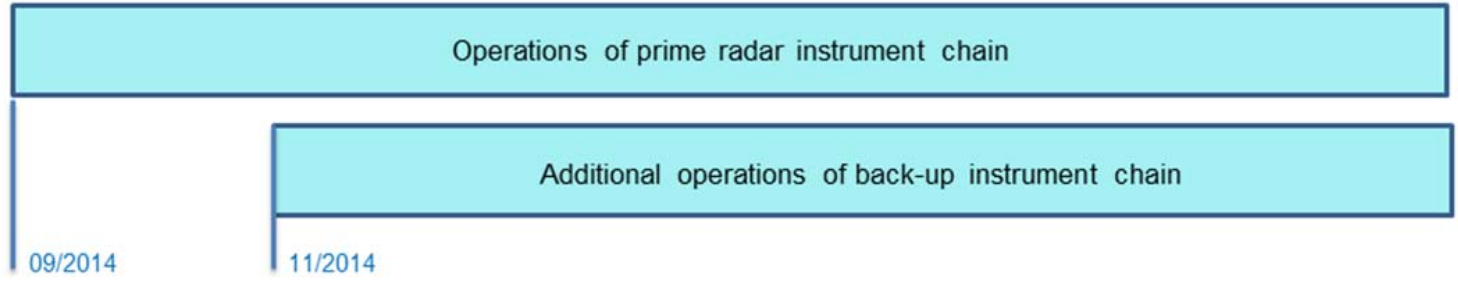

Figure 3 Integration of TanDEM-X science phase into the TanDEM-X mission and subdivision of the science phase into sections. Upper timeline: Data taking for the primary goal of the TanDEM-X mission, the global Digital Elevation Model (DEM), took approximately 4 years. The science phase, dedicated to secondary mission goals succeeded the DEM Phase. This period lasted from September 2014 to February 2016. Since then the TanDEM-X mission focuses on high resolution digital elevation models.

a) Zoom into the TanDEM-X science phase with the focus on formation flight: the formation has been modified all together 15 times. The three major phases are a pursuit, a large cross-track and a close formation. Inbetween the large cross-track and close formation a short transition phase has been inserted. Numbers below the major phases indicate the number of formation changes within the corresponding period (including the entry into this phase).

b) Zoom into the TanDEM-X science phase with the focus on payload operations: the primary radar instrument was operated as usually. Starting from November 2014 the redundant radar instrument chains have been operated in addition for a part of the science data takes.

changes. In addition, extreme, as compared to the previous DEM phase, arrangements of the formation were required. Figure 3 gives an overview of the embedment and the composition of the science phase. Part a) thereby focuses on a classification of formation geometries. The corresponding values for vertical, normal and along-track separation are presented in Figure 4 and Figure 5. Apart from these formation changes, payload operations were significantly altered within the science phase. As outlined in part b) of Figure 3 elements of the redundant SAR instrument chain were operated in parallel to the nominal ones starting from November 2014. This influenced significantly the mission planning process and is subject to different SpaceOps conference contributions ${ }^{10,11}$. The operations of the redundant instrument chain enabled the so-called Dual Receive Antenna (DRA) mode. Here, the SAR antenna of each spacecraft was virtually split in two parts with a displacement of the phase centers in alongtrack direction. Velocity measurements of fast moving objects took advantage of four phase centers on the two satellites ${ }^{9}$.

\section{A. Pursuit formation}

This formation marked the starting point of the science phase in September 2014. TSX was leading the constellation followed by TDX on exactly the same ground-track but with a time offset of 10s. TanDEM-X mission data takes were acquired in the pursuit monostatic mode (see Figure 1e). Here, TSX acquired data of a ground target and TDX probed the identical ground target 10s later. Interferometric measurements of objects moving on the Earth's surface 


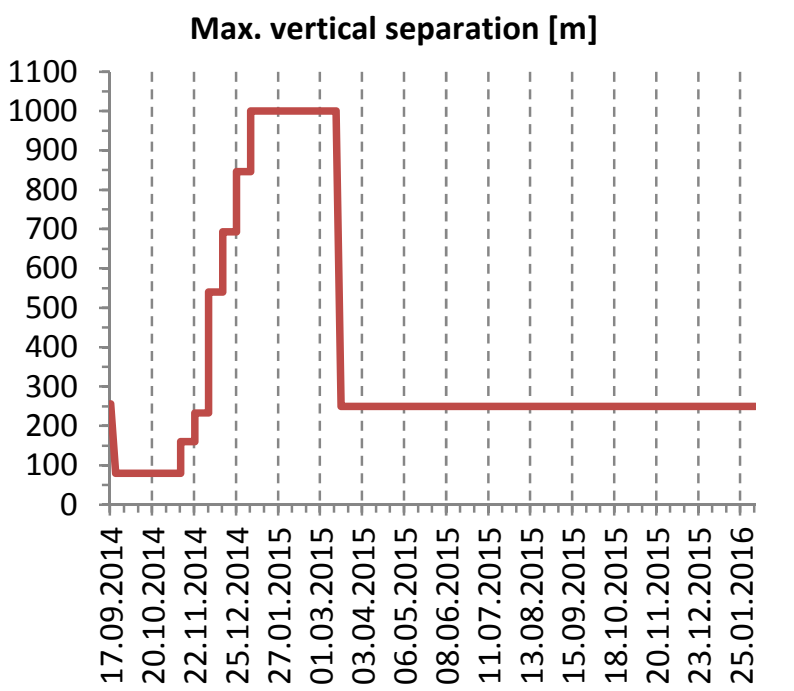

Mean along-track sep. $[\mathrm{m}]$

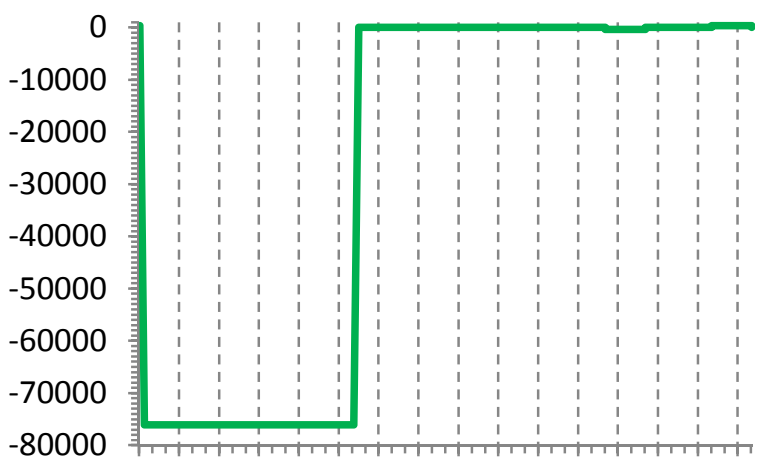

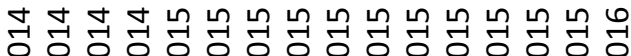

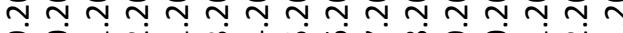

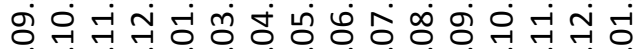

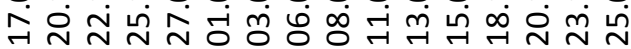

Max. horizontal separation [m]

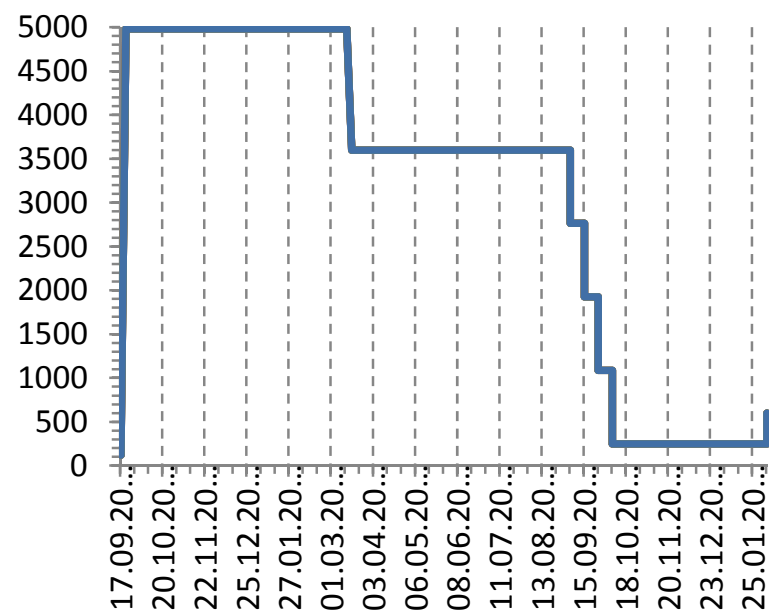

Zoom: Mean along-track sep. [m]

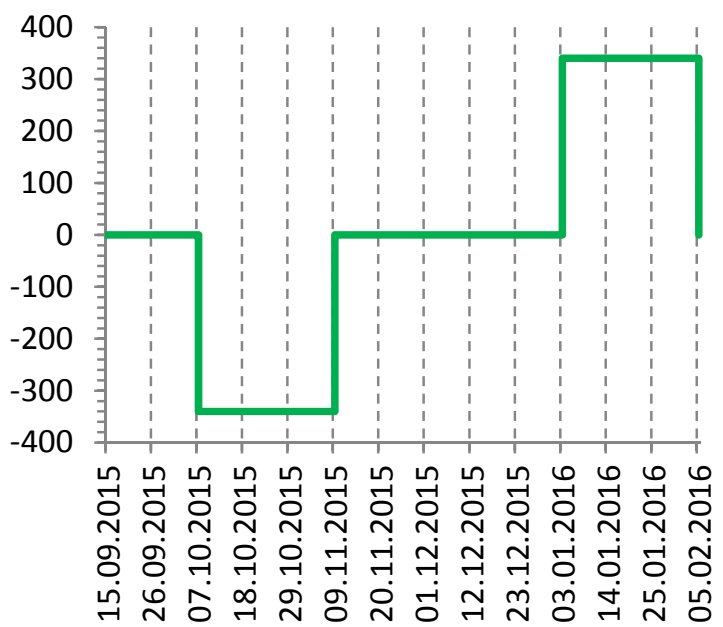

Figure 4 Formation characteristics in the TanDEM-X science phase maximal vertical separation, maximal horizontal separation, and mean along track separation as a function of time

within an adequate velocity range were performed. As a side effect, the TerraSAR-X mission took advantage of the pursuit formation as well. The payloads could probe neighboring targets within a single pass; information on larger target area became thus accessible.

Ten seconds time offset corresponded to a mean along-track difference between the spacecraft of $76 \mathrm{~km}$. The maximal horizontal separation was driven by the requirement of an identical ground track. The value of $4.9 \mathrm{~km}$ was selected in the intention that the horizontal separation counterbalanced the effect of $10 \mathrm{~s}$ Earth rotation on the ground track at any argument of latitude. The size of maximal vertical separation was adjusted several times during the pursuit formation phase. During the DEM phase TDX maneuvers kept the location of the maximal vertical separation close to the Earth's poles, as outlined in Figure 2. Formation control of this type was paused during this period; the natural change on the formation due to Earth's oblateness was not corrected for. Within a 104 day cycle, the location of the maximal vertical separation drifted through 360 deg in argument of latitude. At four points in time within the 104 day cycle both the horizontal and the vertical separation vanished synchronously close to the poles. This could be tolerated since $76 \mathrm{~km}$ along-track separation prevented a collision of the satellites. The temporal change of the relation between vertical separation and argument of latitude resulted in a high degree of variance in interferometric baselines. The diversity of available baselines was even reinforced by a step by step increase of the 
maximal value of vertical separation from $80 \mathrm{~m}$ to $1000 \mathrm{~m}$ (see Figure 4). This constellation was well suited for e.g. tomography applications. In addition, it allowed acquiring additional DEM data to fill remaining gaps in the global DEM with an appropriate baseline.

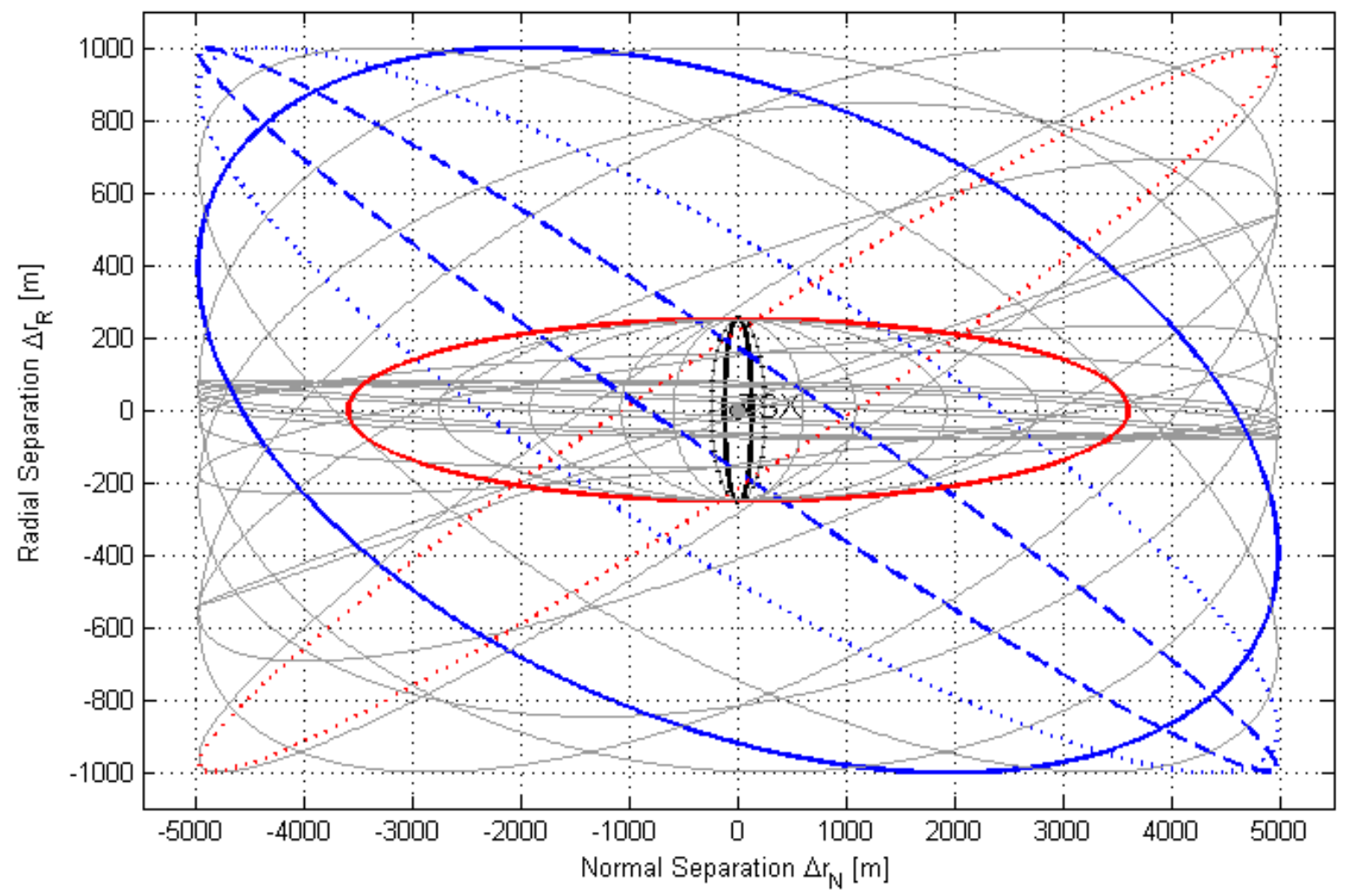

Figure 5 Relative orbit from the TanDEM-X science phase The lines represent exemplary snap shots of the relative motion of TDX with respect to TSX (at position 0,0) in the plane perpendicular to the flight direction. The representation and the axes correspond to Figure 2 a. The formation before entering the TanDEM-X science phase is outlined by the black solid curve (September 17 ${ }^{\text {th }}$, 2014). The last point of the science phase is represented by the dotted line in black (February $\left.5^{\text {th }}, 2016\right)$. All other curves are intermediate states. Blue lines represent states within the pursuit formation (solid line January $5^{\text {th }}$, 2015; dotted line January $16^{\text {th }}$, 2015; dashed line January $27^{\text {th }}$, 2015). Due to the paused relative eccentricity control in the pursuit phase the motion varies with time. The curves resemble ellipses, with course of time they tide, shrivel to a line and expand again. Red curves focus on the transition from the pursuit phase to the large cross track phase. The dotted line represents the final state of the pursuit phase on March $13^{\text {th }}, 2015$, whereas the solid line shows the formation of the large cross track phase. The formation was stable from March $17^{\text {th }}, 2015$ to September $4^{\text {th }}, 2015$.

\section{B. Large cross-track baseline formation}

The transition from the pursuit formation to the large cross-track baseline formation was initiated in March 2015. In contrast to the proceeding constellation the mean along-track separation was set again to zero. Therefore, formation control to counterbalance the natural drift described in point A had to be resumed. The formation would otherwise not have been safe against potential collision. The outstanding feature of this period was the considerable large horizontal separation of $3.6 \mathrm{~km}$. In terms of efficient hydrazine usage, it was favorable that the large cross-track baseline formation followed the pursuit phase. In general corrections of the horizontal separation are expensive in hydrazine. Therefore the high values of $4.9 \mathrm{~km}$ (pursuit formation) and $3.6 \mathrm{~km}$ (large cross-track baseline formation) could be combined in a favorable way. TanDEM-X mission data takes were performed in the bi-static mode. The comparatively large baselines in this phase translated to a very high sensitivity for target height information ${ }^{9}$ : Even very small topography differences in the dynamic range of decimeters, e.g. in the wadden sea, or on agricultural 
fields, or even on sea ice surfaces could be targeted. In addition, this period was also dedicated to measure sensitively subsidence processes by means of Differential SAR Interferometry, and, last but not least, to prepare a high resolution digital elevation model acquisition campaign following the science phase in 2016.

\section{Transition}

Within the transition phase hybrid formations between case B and case D were realized. The horizontal separation has been decreased in four steps, as outlined in Figure 4, from $3.6 \mathrm{~km}$ to $250 \mathrm{~m}$ in the timeframe from September 2015 to October 2015.

\section{Short-baseline close formation}

The close formation within the TanDEM-X science phase resembled more or less the standard formation flight for the DEM generation. Vertical separation and horizontal separation were adjusted to $250 \mathrm{~m}$ each, the mean alongtrack separation to zero or near zero. The motivations for this phase were mainly forest but also glaciological applications. Within two campaigns of 33 days duration each, the mean along-track separation deviated from zero: In October/ November 2015 minus $340 \mathrm{~m}$ was configured, in January/February 2016 the sign was inverted to plus $340 \mathrm{~m}$. In standard formation flight the along-track separation varies between plus/minus the double of the vertical separation (see Figure 2b). Normally, the along-track separation vanishes close to the poles. A deviation of the mean along-track separation from zero caused the along-track separation to vanish at mid-latitudes. Short along-track separations enabled velocity measurements of ocean currents. The first campaign was adapted to the needs of targets in the northern hemisphere, the second one to scenes in southern parts of the Earth.

\section{Operational aspects of the TanDEM-X Science Phase}

Chapter II gave an overview of the operational concept of the combined TerraSAR-X/TanDEM-X mission; Chapter III described the TanDEM-X science phase as it was conceived by the science segment at the DLR Microwave and Radar institute. This chapter focuses on the required adaptations to TSX and TDX operations to support the TanDEM-X science phase.

\section{A. Pursuit formation}

1) Maneuver sequence for the transition into pursuit formation

The transition from the close formation of the digital elevation model to the pursuit phase comprised major orbit changes. Since the orbit of TSX is frozen to the TerraSAR-X reference orbit (see chapter II B), all modifications to the formation were realized through orbit maneuvers executed on TDX.

\begin{tabular}{|c|c|c|c|}
\hline Formation Geometry & $\begin{array}{c}\text { Max. vertical } \\
\text { separation }\end{array}$ & $\begin{array}{c}\text { Max. horizontal } \\
\text { separation }\end{array}$ & $\begin{array}{c}\text { Mean along-track } \\
\text { separation }\end{array}$ \\
\hline $\begin{array}{c}\text { DEM Formation } \\
\text { 2014/09/17 }\end{array}$ & $256 \mathrm{~m}$ & $122 \mathrm{~m}$ & $340 \mathrm{~m}$ \\
\hline $\begin{array}{c}\text { Pursuit Formation } \\
\text { 2014/09/21 }\end{array}$ & $80 \mathrm{~m}$ & $4982 \mathrm{~m}$ & $-76050 \mathrm{~m}$ \\
\hline
\end{tabular}

Table 1: Formation parameter change from the DEM phase to the pursuit formation

In order to perform the transition, TDX was maneuvered 15 times in the timeframe from 2014/09/17 07:30 to 2014/09/21 23:00. The reconfiguration started with a maneuver in flight direction, raising the semi-major axis of TDX by about $90 \mathrm{~m}$ and consequently initiating an along-track drift with a rate of about $800 \mathrm{~m}$ per orbit. At about $5 \mathrm{~km}$ along-track separation, a second tangential maneuver was executed. It further increased the drift rate to about $1.6 \mathrm{~km}$ per orbit. The drift was stopped at the target along-track separation after approximately 3 days and 6 hours. This maneuver was also used to adjust the final vertical separation. The change in horizontal separation was achieved through RAAN correction maneuvers in normal direction over the North Pole (90 deg AOL) or anti-normal direction over the South Pole (270 deg AOL). In total, the necessary velocity increment in normal direction amounted to $5.4 \mathrm{~m} / \mathrm{s}$. This cannot be achieved with a single burn using four $1 \mathrm{~N}$ Hydrazine thrusters. Therefore, eight orbit maneuvers, each with about 5 minutes burn duration, increased the horizontal separation by $550 \mathrm{~m}$ per maneuver. 1.5 orbit periods between two consecutive out-of-plane maneuvers were 
foreseen for cooling-down of the thrusters' flow control valves. One additional RAAN correction maneuver was finally required for the fine-adjustment of the horizontal separation

\section{2) Payload operations and safety against illumination}

During the transition phase, the payload on TDX was not used for the acquisition of data due to the on-going orbit modifications. The TanDEM-X mission therefore paused in these four days. Limitations to the TerraSAR-X mission were reduced to a minimum. All TerraSAR-X mission data takes were executed on TSX, which was available for payload operations during the whole transition phase, except for 11 hours at the beginning of the transition. It had to be ensured that TDX would not be harmed by TSX radar transmission in any possible failure scenario (see chapter II/C/1). TSX radar operations therefore needed to be suppressed as long as TDX was in close proximity. At a spatial separation distance of $5000 \mathrm{~m}$ between both spacecraft, mutual illumination posed no longer a risk; the exclusion zone mechanisms were resumed. The sync warning mechanism (see II/C/3) became obsolete as well as that distance. Potential alternation of the relative geometry due to on-board autonomous thruster usage (see $\mathrm{II} / \mathrm{C} / 2$ ) were uncritical at this point. In unfavorable circumstances, the allowed delta-v for on-board autonomy (see II/C/2) could indeed have led to a reverse of the relative drift in along-track, thus to a re-rapprochement of TDX towards TSX. However, a maximal possible drift rate of $55 \mathrm{~m}$ per orbit period at a distance exceeding $5000 \mathrm{~m}$ would have left enough time for intervention by ground control.

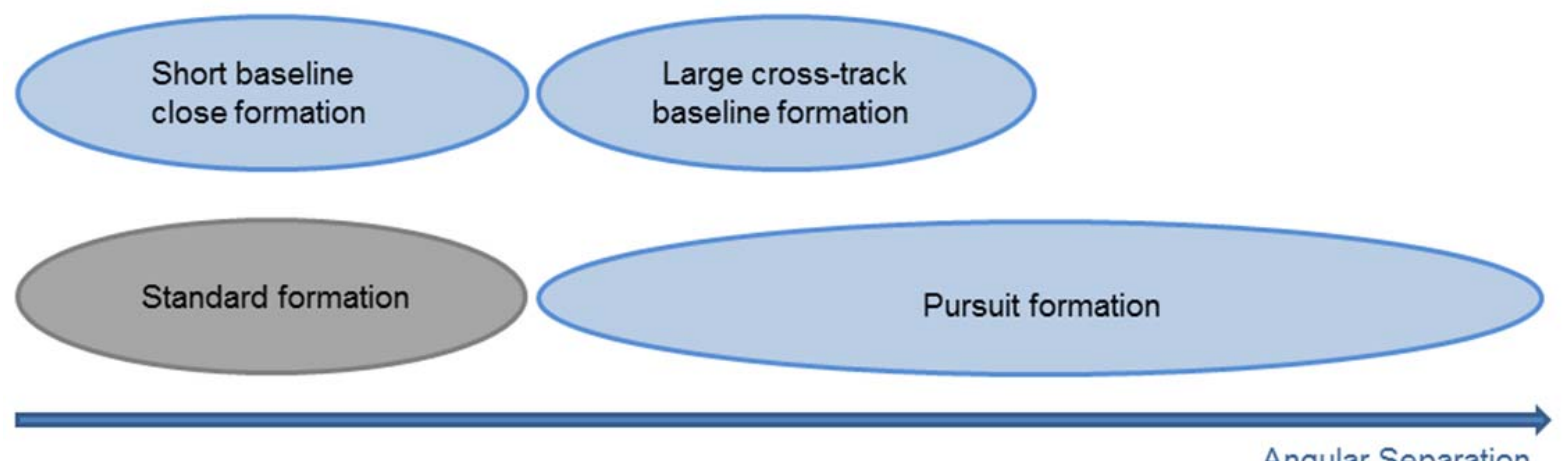

Angular Separation

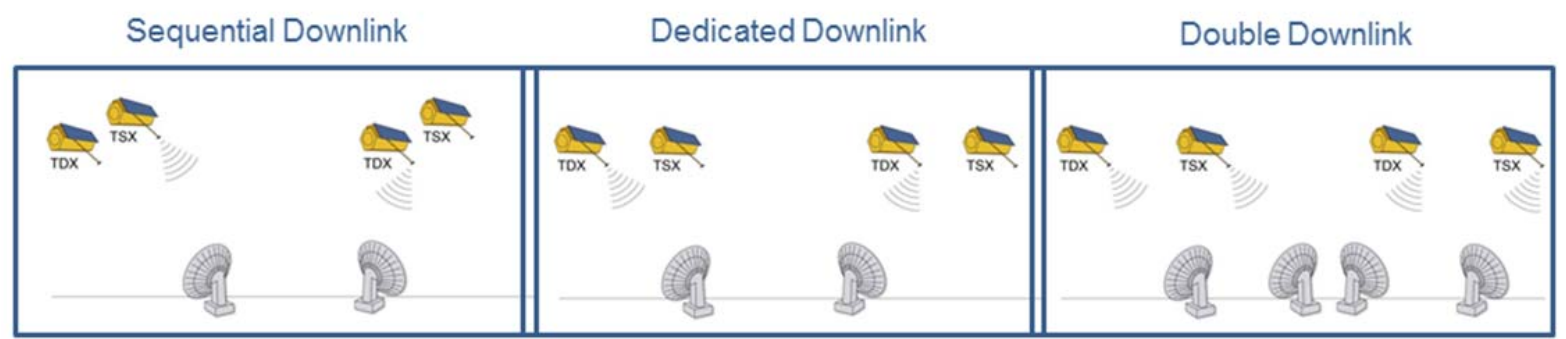

Figure 6 TSX/TDX payload data downlink scenarios

Sequential downlink: within one pass the spacecraft transmit one after the other payload data to one antenna;

Dedicated downlink: either TSX or TDX transmit payload data within one pass;

Double downlink: both spacecraft transmit data simultaneously to two ground antennas.

The upper part addresses which scenario was applied in which part of the TanDEM-X mission.

\section{3) Payload ground station network}

Figure 6 lists options how payload data downlink can be handled within the TerraSAR-X/TanDEM-X mission. In the standard sequential-downlink scenario (see II/D), TSX and TDX alternatingly transmit payload data to the ground antenna during a single overflight. This mode requires close spatial proximity of the satellites which translates to a small, i.e. $<0.1 \mathrm{deg}$, angular separation of both spacecraft, as seen from the ground antenna at all elevation angles. The latter prerequisite was not satisfied in the pursuit phase due to the large separation of TSX and TDX. Sequential payload data downlink was therefore impossible and the scenarios called dedicated downlink and double downlink were used (see Figure 6). Dedicated downlink means that during one overflight either TSX or TDX transmits data. The sharing of the downlink capacity between TSX and TDX was organized 
in a pass-by-pass scheme ${ }^{11}$. A few antennae were assigned to one spacecraft completely to avoid toggling between satellites from the perspective of the ground station. Neustrelitz, the main receiving station for the TerraSAR-X mission, could allocate two antennae for the project. The verification of simultaneous payload data downlinks of TSX and TDX took place during the pursuit constellation; the signals received on ground were not corrupted due to interference. In Neustrelitz, the so called double downlink scenario was thus realized, effectively doubling the available downlink capacity of the main TerraSAR-X mission ground station.

Payload data downlink is performed in the X-Band. Some payload data receiving stations are used in parallel for the uplink of tele commands and telemetry downlink in the S-Band. In the pursuit phase, it was however no longer possible to successfully downlink payload data from TSX and to simultaneously send tele commands to TDX, or vice versa, due to the large separation of the satellites. Therefore, the schedules of S- and X-Band passes had to be harmonized. This was a new situation for the TerraSAR-X/TanDEM-X project. Special attention was paid to the ground station scenario within the transition phase. At its beginning, the on-board memories of TSX and TDX were occupied by data which needed to be downlinked to TerraSAR-X and TanDEM-X mission ground station network (see II/D) within 24 hours. During the transition, the TerraSAR-X mission was running solely on TSX, which had to be reflected in the payload data downlink schedule. The SBand schedule needed to fit the monitoring needs of TSX and, especially, the ones of TDX due to the on-going orbit reconfigurations.

\section{B. Large cross-track baseline formation}

1) Maneuver sequence for the transition from pursuit formation into large cross-track baseline formation

\begin{tabular}{|c|c|c|c|}
\hline Formation Geometry & $\begin{array}{c}\text { Max. vertical } \\
\text { separation }\end{array}$ & $\begin{array}{c}\text { Max. horizontal } \\
\text { separation }\end{array}$ & $\begin{array}{c}\text { Mean along-track } \\
\text { separation }\end{array}$ \\
\hline $\begin{array}{c}\text { Pursuit formation } \\
2015 / 03 / 13\end{array}$ & $1000 \mathrm{~m}$ & $4982 \mathrm{~m}$ & $-76050 \mathrm{~m}$ \\
\hline $\begin{array}{c}\text { Large cross-track } \\
\text { baseline formation } \\
\text { 2015/03/17 }\end{array}$ & $250 \mathrm{~m}$ & $3600 \mathrm{~m}$ & 0 \\
\hline
\end{tabular}

Table 2: Formation parameter change from the pursuit formation to the large cross-track baseline formation

The formation reconfiguration started with a TDX maneuver in anti-flight direction, which lowered the semimajor axis of TDX by about $500 \mathrm{~m}$ and installed an along-track drift towards TSX with a drift rate of about $4700 \mathrm{~m}$ per orbital revolution. The necessary velocity increment in normal direction amounted to $1.53 \mathrm{~m} / \mathrm{s}$. Two RAAN correction maneuvers step-wise decreased the normal separation from $4982 \mathrm{~m}$ to $3600 \mathrm{~m}$. At about $10 \mathrm{~km}$ along-track separation the second tangential maneuver toke place and stopped the drift. This intermediate stop was introduced to safely change the relative eccentricity vector. In addition, the intermediate stop was foreseen to prevent a too fast along-track approach and therefore precluded illumination problems by TSX.

\section{2) Payload operations and safety against mutual illumination}

The transition from the pursuit formation to the large cross-track baseline formation entailed a change back from a safe situation with large inter-satellite distances back to a formation with, at least in parts of the orbit, close proximity of TSX and TDX. The large maximal cross-track separation of $3.6 \mathrm{~km}$ was achieved at the equator crossings, and in polar regions the inter-satellite distance decreased to $250 \mathrm{~m}$. Consequently, the illumination risk was not negligible (see II/C/1). Compared to the transition to the pursuit formation, the sequence of the transition phase for payload operations was inverted: TerraSAR-X mission on TSX without restrictions at distances exceeding $5000 \mathrm{~m}$, no payload operations for smaller separations. Exclusion zone and sync-warning mechanisms were resumed as soon as the transition phase was completed and the relative geometry stable.

Sync warnings exchange status information using sync horns, primarily used for phase synchronization of the TSX and TDX SAR instruments (see II/C/3). Within the large cross-track baseline formation, the sync warning 
mechanism worked in polar regions only. This was shown prior to the phase in the scope of investigations by the DLR Microwave and Radar Institute. Since SAR data takes or maneuvers also prevent a successful sync information exchange, the rare polar opportunities for sync pulse exchange were restricted even further. Altogether, the availability of one opportunity for sync exchange was considered a realistic frequency from operations point of view. During the DEM phase, sync pulses were exchanged at least every 53 min before radar transmission. It had to be analyzed whether a reduced frequency of once-per-orbit would be compliant to the safety concept of the TanDEM-X formation flight. The timing of 53 min in standard formation was based on predictions how soon after a safe mode drop induced thruster activation by on-board autonomy could be required for assistance in attitude control. As described in section II/C/2), the thruster firing is in a first step limited to a maximum allowed velocity increment. The effect of a momentum increase of that size on the formation was analyzed for all possible spatial directions. It could be shown that, in the large-cross track baseline formation, the impact on the exclusion zones size is small, namely in the order of 1 degree in argument of latitude. A respective margin could cover the latter uncertainty; an adequate widening was introduced in the exclusion zone pre-calculations conducted by the DLR Microwave and Radar Institute. Thus, thruster activation until the defined threshold on-board did not pose an illumination risk; the sync warning interval could be set to $100 \mathrm{~min}$.

Due to the large cross-track separation of TSX and TDX in parts of the orbit, TerraSAR-X mission data takes that were executed on TDX experienced a significant displacement from the TerraSAR-X reference orbit. These data takes are less suitable for some TerraSAR-X mission application. In order to minimize the impact of the TanDEM-X science phase on the TerraSAR-X project the so-called preferred satellite concept was applied ${ }^{11}$. TerraSAR-X mission data takes were scheduled primarily on TSX. TDX was selected in case of an according user specification, if the on-board resources of TSX were depleted, or in case the downlink of the data take was requested to an antenna reserved for TDX. The preferred satellite concept had already been introduced at the end of the pursuit formation. The reason at that time was the large vertical separation. However, the main application was during the large-cross track formation.

\section{3) Ground station network}

From the perspective of a ground station, the angular separation of TSX and TDX during the large cross-track phase strongly depended on the geolocation of the respective antenna. While polar stations experienced a constellation similar to close formation flight, antennae at mid-latitudes could not simultaneously track both spacecraft. As outlined in Figure 6, a mix of the modes sequential downlink and dedicated downlink was applied. For Svalbard ground station, sequential payload data downlink was possible. For further X-Band receiving stations at higher latitude, a detailed investigation on the dependency of the angular separation on the elevation was made for each pass in the 11-days repeat cycle. Resulting from this analysis, a few single, highelevation passes with large angular separations were excluded for sequential downlink and assigned to a single satellite instead. Neustrelitz ground station further supported the TerraSAR-X mission with two antennae, one tracking TSX and one TDX. Thus, sequential downlink was possible for NSG. However, the double downlink scenario applied in the pursuit phase was no longer feasible, as interference resulting from TSX and TDX downlinks would have corrupted the signal. The downlink scenario for NSG is not shown in Figure 6.

\begin{tabular}{|c|c|c|c|}
\hline Formation Geometry & $\begin{array}{c}\text { Max. vertical } \\
\text { separation }\end{array}$ & $\begin{array}{c}\text { Max. horizontal } \\
\text { separation }\end{array}$ & $\begin{array}{c}\text { Mean along-track } \\
\text { separation }\end{array}$ \\
\hline $\begin{array}{c}\text { Large cross-track baseline } \\
\text { Formation }\end{array}$ & $250 \mathrm{~m}$ & $3600 \mathrm{~m}$ & 0 \\
\hline $\begin{array}{c}\text { Transition phase: step 1, } \\
\text { 2015/09/04 }\end{array}$ & $250 \mathrm{~m}$ & $2763 \mathrm{~m}$ & 0 \\
\hline $\begin{array}{c}\text { Transition phase: step 2 } \\
\text { 2015/09/15 }\end{array}$ & $250 \mathrm{~m}$ & $1925 \mathrm{~m}$ & 0 \\
\hline $\begin{array}{c}\text { Transition phase: step 3 } \\
\text { 2015/09/26 }\end{array}$ & $250 \mathrm{~m}$ & $1088 \mathrm{~m}$ & $-340 \mathrm{~m}$ \\
\hline $\begin{array}{c}\text { Short baseline close formation } \\
\text { 2015/10/07 }\end{array}$ & $250 \mathrm{~m}$ & $250 \mathrm{~m}$ & 0 \\
\hline
\end{tabular}

Table 3: Formation parameter changes from the large cross-track baseline formation to the short baseline close formation. 


\section{Transition from the large cross-track baseline formation to the short baseline close formation}

The horizontal separation of the large cross-track baseline formation was stepwise decreased from $3.6 \mathrm{~km}$ to $250 \mathrm{~m}$ in order to re-establish close formation flight. At the dates listed in Table 3 a pair of RAAN correction maneuvers (North Pole in negative normal direction, South Pole in positive normal direction) was performed. There was no need to interrupt payload operations during this transition. The sync warning surveillance was intensified again; expiry period of sync warnings was reduced $53 \mathrm{~min}$, in accordance to the setting within the DEM phase. At step 1 the opportunities for sync warning were still limited to polar regions. Avoidance of conflicting data takes ensured sufficient opportunities for sync warnings. The configuration of the payload ground station network was identical as compared during the large-cross track phase; at least as concerned the TanDEM-X network and the primary ground station Neustrelitz of the TerraSAR-X mission.

\section{Short baseline close formation}

The close formation flight within the TanDEM-X science phase resembled largely the constellation during DEM data acquisition; therefore the principles described in chapter II apply. Two TanDEM-X Autonomous Formation Flying (TAFF) campaign were performed, with a duration of 33 days each (section III/D). TSX GPS solution is sent via a uni-directional S-Band inter-satellite to TDX. Its on-board software is able to plan and execute on-board autonomously formation control maneuvers to maintain a ground commanded target formation. Formation control maneuvers make use of a TDX cold-gas orbit control system. These TAFF campaigns became necessary to achieve an along-track control accuracy of better than $20 \mathrm{~m}$. Most of the time formation control is done with ground in the loop, not using the available on-board autonomy. The TDX TAFF concept was operationally validated for formation control during TAFF campaign within the DEM phase ${ }^{12}$.

\section{Conclusion}

TerraSAR-X and TanDEM-X mission are in routine operations since January 2008 and January 2011 respectively. The TanDEM-X science phase posed a major challenge to the operations team because concepts established since many years needed to be modified. Furthermore, many components of the ground software system had to be upgraded. The enhanced versions needed to be thoroughly tested and integrated into a fully operational ground system with a minimum of maintenance outages ${ }^{11}$. Validation campaigns for each new constellation were undertaken to prove compliance of the system with respect to the requirements of the TerraSAR-X and TanDEM-X mission $^{11}$. The handling of the ground station network for payload data downlink was subject to a number of studies within the mission planning system ${ }^{11}$. It was not trivial to assign the payload data downlink opportunities to the satellites TDX and TSX in a way that the overall downlink capacity was somewhat equally shared and all boundary conditions were fulfilled. Therefore the payload ground station handling was subject to many configuration adaptations within the TerraSAR-X/TanDEM-X mission planning system ${ }^{11}$. Especially, the transitions from one constellation to the following were challenging. The maneuver sequence had to be planned, safety aspects needed to be assessed and mission planning had to adapt to the evolving constellations. The transitions were carefully planned; aspects concerning flight dynamics, safety, on-board modifications and mission planning were assessed and findings were documented prior to the transition. In conclusion the TanDEM-X science phase was successfully handled and all requirements of the science segment could be fulfilled. The satellite operations ran very smoothly without any significant problems.

\section{Acknowledgments}

The authors thank the colleagues of the TerraSAR-X/TanDEM-X ground, science and commercial segment for the very good cooperation in general and especially for their contributions to TanDEM-X science phase operations.

\section{References}

${ }^{1}$ Schättler, B., Kahle, R. ,Metzig, R., Steinbrecher, U. , Zink, M. (2011)“The Joint TerraSAR-X / TanDEM-X Ground Segment“. Proceedings of Geoscience and Remote Sensing Symposium (IGARSS), 2011, Vancouver, Kanada, pp. 2298-2301, ISBN 978-14577-1003-2., ISSN 2153-6996

${ }^{3}$ Krieger, G., Moreira, A., Fiedler, H., Hajnsek, I., Werner, M., Younis M., Zink, M., “TanDEM-X: a satellite formation for highresolution SAR interferometry”, IEEE Trans. Geosci. Remote Sens. 45. 2010, pp. 3317-3341.

${ }^{3}$ Krieger, G., et al., “TanDEM-X: a radar interferometer with two formation-flying satellites”, Acta Astronaut. 89, 2013, pp. 8398.

${ }^{4}$ Kahle, R., Schlepp, B., Meissner, F., Kirschner, M., Kiehling, R., ”The TerraSAR-X/TanDEM-X Formation Acquisition-From Planning to Realization“, Journal of the Astronautical Sciences. 59 (3), 2014, ISSN 0021-9142 
${ }^{5}$ Kahle R., D'Amico S., “The TerraSAR-X Precise Orbit Control Concept and Flight Resuluts”, International Symposium on Space Flight Dynamics (ISSFD), 2014, Laurel USA, http://issfd.org/ISSFD_2014/ISSFD24_Paper_S1-3_Kahle.pdf.

${ }^{6}$ Kahle, R., Schlepp, B., Aida, S., Kirschner, M., Wermth, M. "Flight Dynamics Operations of the TanDEM-X Formation” Stockholm, Schweden : s.n., 2012. Proceeding of the 12th International Conference on Space Operations. Jun 11th-15th 2012.

${ }^{7}$ Maurer, E., Zimmermann, S., Mrowka, F., Hofmann, H., "Dual Satellite Operations in Close Formation Flight", Proceedings of the 12th International Conference on Space Operations, 2012, Stockholm, Schweden, Jun 11th-15th 2012

${ }^{8}$ Metzig, R., Diedrich, E., Reissig, R., Riffel, F., Henniger, H. , Schättler, B., The tanDEM-X Ground Station Network.“ Proceedings of Geoscience and Remote Sensing Symposium (IGARSS), 2011, Vancouver, Kanada, pp 902-905, ISBN 978-14577-1003-2, ISSN 2153-6996

${ }^{9}$ DLR TanDEM-X science phase site: https://tandemx-science.dlr.de/pdfs/TD-PD-PL_0032TanDEM-X_Science_Phase.pdf

${ }^{10}$ Mrowka, F., Göttfert, T., Wörle, M. Th., Schättler, B., Stathopoulos, F., "The TerraSAR-X/TanDEM-X Mission Planning System: Realizing new customer visions by applying new upgrade strategies", Proceedings of the 16th International Conference on Space Operations, 2016, Daejeon, Korea, May $16^{\text {th }}-20^{\text {th }} 2016$

${ }^{11}$ Stathopoulos, F., Guillermin, G., Garcia Acero, C., Reich, K., Mrowka, F., "Evolving the Operations of the TerraSAR$\mathrm{X} /$ TanDEM-X Mission Planning System during the TanDEM-X Science Phase.”, Proceedings of the 16th International Conference on Space Operations, 2016, Daejeon, Korea, May $16^{\text {th }}-20^{\text {th }} 2016$

12 Ardaens, J.-S., Kahle, R., Schulze D., "In-flight performance validation of the TanDEM-X autonomous formation flying system”, International Journal of Space Science and Engineering. 2, 2014, Bd. 2, pp. 157-170. DOI: 10.1504/IJSPACESE.2014.060596. ISSN 2048-8459 